\title{
A CAUSE OF COMMUNICATION FAILURE IN MANAGING INDUSTRIALIZED BUILDING SYSTEM (IBS) PROJECTS: A PERSPECTIVE VIEW FROM PROJECT MANAGERS
}

\author{
Mohd Affendi Ahmad Pozin ${ }^{1 *}$, Mohd Nasrun Mohd Nawi ${ }^{1}$, Angela Lee ${ }^{2}$, Mazri Yaakob ${ }^{1}$, \\ Mohd Hanizun Hanafi ${ }^{3}$ \\ ${ }^{1}$ School Technology Management and Logistics, Universiti Utara Malaysia, \\ 06010 Sintok, Kedah, Malaysia \\ ${ }^{2}$ School of the Built Environment, University of Salford, M5 4WT Manchester, UK \\ ${ }^{3}$ School of Housing, Building and Planning, Universiti Sains Malaysia, 11800 Penang, Malaysia
}

(Received: July 2018 / Revised: September 2018 / Accepted: December 2018)

\begin{abstract}
An effective communication process is an important element in distributing information to various project teams. The previous study demonstrates the importance of communication in the project management process in order to encourage project delivery processes successfully. Unfortunately, the issue of communication still dominates Industrialization Building System (IBS) because the project development process are still based on traditional methods. This research aims to explore the cause of communication challenges between construction players in managing IBS projects. The research methodology implemented for this paper was a semistructured interview approach used to investigate the communication problem. Five experienced project managers were chosen from across the industry. The findings of this study are valuable for improving the communication level of project teams, which will indirectly increase the level of the IBS project delivery process and strengthen team integration on IBS projects in Malaysia.
\end{abstract}

Keywords: Communication issues; Industrialized Building System (IBS); Leadership; Project management

\section{INTRODUCTION}

Communication is recognized as an important factor for success in a global business environment. Effective communication is becoming increasingly important in project construction because of the growing demands of the projects, along with the heavy amounts of technical work and the complexity of the supply chain process. Current situations saw that construction projects involving multi-organizations containing different organizational backgrounds, cultures, diverse stakeholders and areas of expertise (Firmawan et al., 2012). An effective communication process could minimize the issue of human relationships and increase the integration and collaboration among construction players. This process will affect all construction work activities by increasing timely information sharing and improving decisionmaking. Therefore, effective communication becomes a core element to increase project performance and decrease project risk.

In Malaysia, the main problem on a construction project is still the lack of communication (Nawi et al., 2018). This issue remains because most of the construction industry is still 
dominated by the traditional construction approach. The traditional construction approach created a complex communication process due to the fragmentation of parties, long life cycles on construction project and multiple organization structures (Alashwal \& Fong, 2015). For example, the coordination between design and planning process by distributed professionals from a different location (Othman et al., 2017). In contrast, to develop an Industrialized Building System (IBS) on a construction project, effective communication is required to integrate the team. This too ensures effective management process of the manufacturing, transportation, and assembly process, which will reduce cost, time, and improve the quality of the product.

In this situation, a qualified and experienced project manager is required to manage the complexity of the communication process in order to achieve successful deliveries. To address the knowledge gap at the project delivery level, this paper will present semi-structured preliminary interviews. The findings with concern to the lack of a communication process by identifying the cause of the communication problem between project team members in order to manage IBS project effectively.

\subsection{An Overview Toward IBS Project}

Today, the Malaysian construction industry is under pressure to deliver and tackle the issues of performance, safety, demand (especially to deliver affordable housing), and environmental and sustainability concerns. To cope with these challenges, in 2016 the Construction Industry Development Board (CIDB) launched the Construction Industry Transformation Programme (CITP 2016-2020) as a strategy to improve the construction industry by utilizing the IBS method as a solution; even though IBS adoption in Malaysia has long historical note since the 1960s (CIDB, 2016). The IBS method offers huge advantages and benefits for productivity and the quality of building construction. The IBS process is systematically re-arranged, which the component is started manufactured at the factory, either on-site or off-site. Further, the component will be delivered to the construction site to be assembled and erected. This process could improve sustainable practices by incorporating integrated design, fully utilized of material usage, reducing construction waste of material, minimize site disturbance and noise (Othman et al., 2017). In this project, effective communication skill between project teams is required to coordinate the process and deal with critical scheduling points from the beginning of the project through to its completion. The increasing number of project size, segregation of a large number small firms, separation of the design and construction stage, and the limited team coordination and integration, forces construction projects to need an effective construction manager who can initiate, plan, execute, monitor and close a whole project or a portion of a project.

\subsection{Project Manager Role}

IBS projects are assumed to be very complex to define and manage the material and contractual links throughout supply chain because the project is based on segregation of professional during the design and construction phase. The complexity from the construction process required a competency and qualified organization led by a competent constriction manager to managing the project successfully. The project manager is the person who facilitates the overall construction project management process. The project manager needs to monitor, plan, execute and initiate the whole of the project in order for it to progress smoothly. Moreover, project managers should have additional competencies such as skill, knowledge, behavior, and ability to handle unexpected situations (Sunindijo, 2015). As state by Dainty et al. (2006), the combination of technical knowledge and expertise can ensure effective coordination and communication from different stakeholders (Dainty et al., 2006). Effective communication styles differ between leaders but communication with people remains a basic element of 
leadership. This study does not discuss leadership styles intrinsically, but leadership styles influence the effectiveness of communication. Therefore, a review of leadership styles is important. The styles may be applied individually, selectively or in combination, depending on the situation. Below table outlining the general leadership styles in business management practices (Table 1).

Table 1 Leadership style in business management practices

\begin{tabular}{|c|c|c|}
\hline Leadership style & Description & References \\
\hline $\begin{array}{l}\text { Contingency or } \\
\text { situational leadership } \\
\text { style }\end{array}$ & $\begin{array}{l}\text { Concerned with the appropriateness of } \\
\text { different leadership styles in different } \\
\text { leadership situations by matching the } \\
\text { personal characteristics of a leader in the } \\
\text { leadership situation. }\end{array}$ & (Müller et al., 2010) \\
\hline $\begin{array}{l}\text { Sloan or visionary } \\
\text { leadership style }\end{array}$ & $\begin{array}{l}\text { The visionary is an analytical thinker and is } \\
\text { achievement orientated. This leader enlists } \\
\text { others by involving them, listening to them, } \\
\text { and clearly communicating with them. }\end{array}$ & $\begin{array}{l}\text { (Müller et al., 2010); } \\
\text { Meng \& Boyd, } \\
\text { (2017) }\end{array}$ \\
\hline $\begin{array}{l}\text { Life cycle leadership } \\
\text { style }\end{array}$ & $\begin{array}{l}\text { Known as the contingency approach. This } \\
\text { leader aims to achieve a balance between } \\
\text { the task and relationship. }\end{array}$ & $\begin{array}{l}\text { (Hersey \& } \\
\text { Blanchard, 1972) }\end{array}$ \\
\hline $\begin{array}{l}\text { Action centered } \\
\text { leadership style }\end{array}$ & $\begin{array}{l}\text { Focused on leadership action for the task, } \\
\text { team, and individual. They focus on each } \\
\text { one at different times in order to deal with } \\
\text { specific needs. }\end{array}$ & $\begin{array}{l}\text { (Burke \& Barron, } \\
\text { 2014) }\end{array}$ \\
\hline
\end{tabular}

Moreover, as a state by Campbell (2011), "good communication and strong leadership go hand in hand". That means a successful project manager is someone who was manages projects on time, within budget, and effectively manages the interactions and communications between people and organizations. Barrett (2008) suggested that in a complex organization there are three components to improving the communication skills of project managers. First, the need to expend from core strategy development. Second, the improvement of the manager's writing and speaking abilities. Finally, the manager's must improve their core communication skills to become effective communicators.

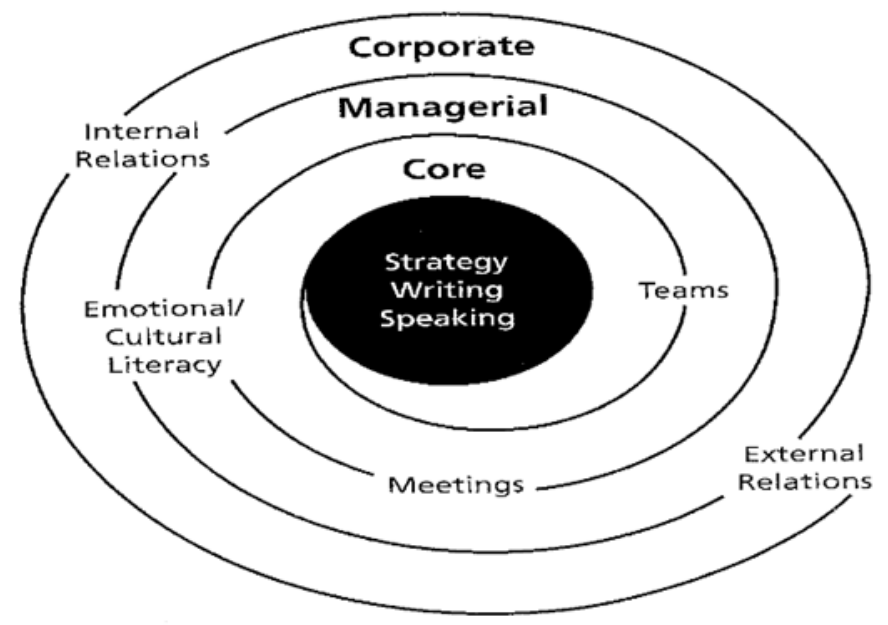

Figure 1 Barrett Spiral Communication Model (Barrett, 2006) 
Below are descriptions of the sections in the leadership communication framework found in Figure 1:

a) The core skills are writing and speaking. The project manager must be able to use these skills to deliver a good presentation and to persuade and impress readers with their words.

b) Project managers need be able to listen in any given situation and pay attention to what others are saying. This ability applies to the management ring for managing others effectively. The managerial rings may also include key meetings, team building, and the team development process.

c) Cooperate communication is essential to help organizations explain their vision, mission, and values in a cohesive message to stakeholders. It could be seen as an integrative communication structure linking stakeholders to the organization.

\subsection{Structure Project Organizations}

There are multiple organizations involved in a construction project. The increasing project size is related to the involvement of different alliance organizations and non-alliance organizations (i.e., local authority) and their different demands. The entire organization from the distributed area are difficult to integrate because of the different heterogeneous system used belong to the organization practices on the project. For instance, on IBS projects each stage incorporates various stakeholders and different communication instruments (Shukor et al., 2016). Different communication instruments include: plan drawings, reports, computer files, catalogues, instruction manuals, notes, memos, models, photographs, and meeting minutes. All this information should be synchronized to the different types of workers by linking it to the internal site project (Abedi et al., 2016). Without effective communication, collaboration, and integration it is difficult to develop this information cycle, especially for the storing, sharing, and managing the information. This often results in conflict and litigation between project team members.

\subsection{Supply Chain and Logistics Management Process}

IBS projects require effective monitoring controls in the supply chain process. According to Ismail et al., (2016), supply chain structure is very complex in its connectivity with various interdependent groups, organizations, individuals, and relationships. In IBS projects, it is very important to ensure the supply chain process is efficient because there are many challenges to delivering the IBS construction components, such as site location, demographics, and conjunction (Kassim \& Walid, 2013). Figure 2 illustrates how an IBS project delivery process is conducted.

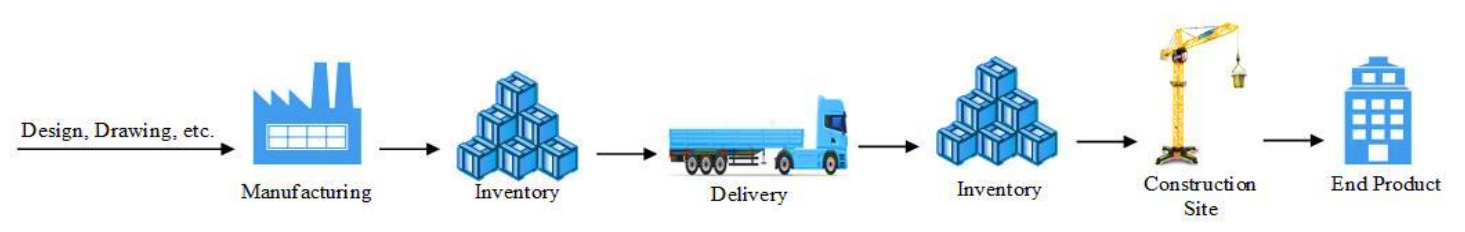

Figure 2 Illustrated IBS project delivery process

Currently, most of IBS manufactures are located in the Klang Valley area. Thus, to deliver a deliver a large-sized component is difficult because the location is far away from rural areas (Fauzi et., 2017). Successful planning among project teams is required to ensure estimated delivery times of IBS components are in-line with the preparation of the site project. Therefore, open communication must exist between all practitioners (owner, engineer, supplier, and contractor) in decision-making, designing, transporting, and scheduling. As a result, there are 
related problems when the communication process was not effective in the supply chain for a construction project. The related issues are as follows:

a) Misconceptions and misunderstandings in obtaining and analyzing the information.

b) Lack of integration between every construction phase during the project delivery process.

c) Without an effective communication channel, the differences in cultures, languages, and organizational cultures can lead to a lack shared knowledge and skills, heightened egotistic attitudes, and lack of consideration between teams.

d) Less cooperation between higher authorities because they are reluctance to accept other members' opinions and bureaucracy in the organization's structure.

e) The different trade and task from different teams could effect on bypass the work, working attitude and commitment.

\section{METHODS}

This research was done by interviewing project managers which practically manage the IBS construction project in Malaysia. The qualitative approach, the semi-structured face-to-face interview, was used to gain in-depth information and an overall perspective from a variety of construction professionals, which included five project participants, who are project managers at different construction firms, a client, a consultant, and a contractor (Table 2). According to Abdul Nifa, (2013) a semi-structured interview is considered to be advantageous because it can be modified based upon the interviewers perception of what seems most appropriate. Additionally, the data from semi-structured face-to-face interviews is reliable, controlled, and the data collection can be fast because of the same format is used with each respondent (Irvine et al., 2010). The answers from the interview phase can be further elaborated and detailed via a set of questions the interviewer completes based on the interviewee's response.

Table 2 Interview of the respondents

\begin{tabular}{ccccc}
\hline Name & Position & Working Experience & Discipline & Gender \\
\hline Respondent 1 & Project Manager & 10 & Manufacturer & Male \\
Respondent 2 & Project Manager & 16 & Consultant & Male \\
Respondent 3 & Project Manager & 10 & Consultant & Male \\
Respondent 4 & Project Manager & 15 & Contractor & Male \\
Respondent 5 & Project manager & 20 & Supplier & Male \\
\hline
\end{tabular}

The data gathered from the semi-structured interview has been analyzed using the content analysis technique. The text from respondents was encrypted, counted, and recoded in the frequency distribution table. The raw data is organized and assembled into template analysis, which refers to the process of organizing and analyzing textual data according to codebook analysis or thematic coding (Crabtree \& Miller, 1999). Moreover, Saunders et al. (2009) further described that the essence of the approach is that the researcher produces a list of codes or categories (template) that represent the themes or issues revealed from the data that has been collected. This code is very important to the researcher for the interpretive process. As discussed by King (2004), some of the codes will usually be defined as a priori, but they will be modified and added to as the researcher reads and interprets the texts. In contrast to other techniques, template analysis is a flexible technique with less specified procedures that permits researchers to tailor it to match their requirements. It works particularly well when the research aim is to compare the perspectives of different groups of staff within a specific context. 


\section{RESULTS AND DISCUSSION}

In this study, an intensive analysis of data focuses on the cause of the lack of communication in the construction industry. The findings are looked at based on Quality of Information and Knowledge, lack of skill and attitude-related issues and organization structure which are necessary to discuss. Table 3 discusses the cause of communication issues from the project managers' perspective while managing IBS construction projects.

Table 3 The dimensions of the causes of communication problems

Dimension
As indicated by respondent R2, communication between the project team should
be clear especially when it relates to the technical aspects of a project. The
problem affects design and quality.
"When the instruction not clear between architecture, team structure and
engineer in determined specific size of the component, the design of the
component didn't meet the standard size from the architect." -R2
When multiple disciplinary areas need to share specific information it can be
challenging. Essentially, when the decision-making is not accurate and multiple
disciplinary teams are not cooperating, effective decision-making for a certain
task is difficult. This is indicated by experience from the respondent R3.
"Less cooperation within teams project at the site, namely (clients, designers,
contractors, system providers/manufacturers and installers) on IBS supply chain
process. While there should communicate together in planning for what the
material is being used by specific item. The mistakes were harming the of the
operation".-R3
Project teams are less understanding and familiarity with IBS components is low
due to the limited availability of system providers and manufacturers in the
market. As suggested by previous studies, poor human capital development
regarding knowledge and understanding of the Industrialized Building System
(IBS) and Supply Chain Management (SCM) affects the whole construction
supply chain and hinders integration.




\begin{tabular}{|c|c|}
\hline Dimension & Problem \\
\hline \multirow{5}{*}{ 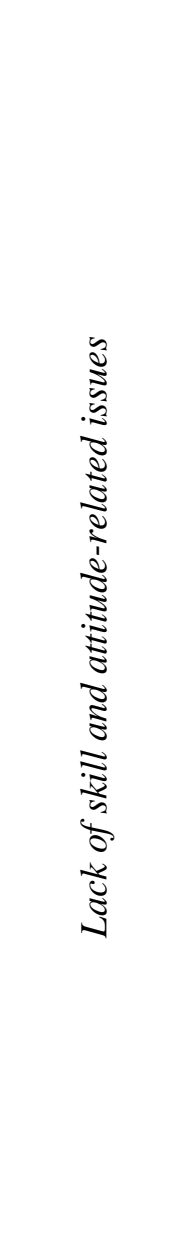 } & $\begin{array}{l}\text { The human-related factors associated with soft issues, such as attitude, are } \\
\text { difficult to measure compared to hard issues in a project, such as stakeholders' } \\
\text { technical competency, project financing, and quality of workmanship. This is } \\
\text { point is illustrated by respondent R5. }\end{array}$ \\
\hline & $\begin{array}{l}\text { "Normally we use a fax for transmission of documentation to make a reservation } \\
\text { to the supplier. But what happens is the person in charge is not responsible when } \\
\text { receiving orders from our party. The reason given is that reservations are not } \\
\text { accepted and there is a record from our party. This happen because from the } \\
\text { attitude of workers is less efficient in managing their work".-R5 }\end{array}$ \\
\hline & $\begin{array}{l}\text { The importance of employee training for the team is essential to ensure they } \\
\text { know the job description and list of daily duties. These should be clear according } \\
\text { to their position. Once a job description and duty are known, the smallest } \\
\text { mistakes can be avoided. According to respondent R4, even though construction } \\
\text { sites are usually well organized and carefully planned, sometimes even the best } \\
\text { construction managers overlook some tasks. }\end{array}$ \\
\hline & $\begin{array}{l}\text { "Often occurs when a person had to go through the assigned high workload, as } \\
\text { examples of his work as a document controller to update the document into the } \\
\text { system, when high burdens are accepted, he will be overlooked for the uploaded } \\
\text { document. Therefore these individuals should be proactive and smart in dealing } \\
\text { with this problem".--R4 }\end{array}$ \\
\hline & $\begin{array}{l}\text { These results are consistent with the factors previously outlined in the project } \\
\text { manager role. Studies have shown that negative attitudes, such as arrogance, } \\
\text { selfishness, short-term focus, and ignorance to the needs and contributions of } \\
\text { others, prevent integration of construction supply chains. }\end{array}$ \\
\hline \multirow{2}{*}{ 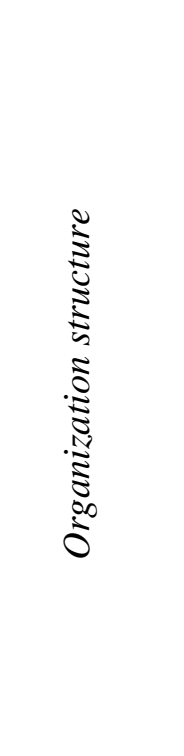 } & $\begin{array}{l}\text { Open and direct communication can create a sense of transparency in the } \\
\text { organizational structure. It could build a level of trust between employees. In } \\
\text { turn, this would make a more positive work environment and develop staff who } \\
\text { feel secure and safe. Open communication can reduce feelings of uncertainty and } \\
\text { cluelessness about the company. These feelings often result in resentment, } \\
\text { tension, and a feeling of low job security. According to respondent R1, } \\
\text { organizational structures that are generally inflexible and centralized with rules } \\
\text { and regulations creates bureaucracy in the organization. This creates difficulties } \\
\text { in the decision-making process for staff in the organization. As stated by the } \\
\text { respondent (R1); }\end{array}$ \\
\hline & $\begin{array}{l}\text { "The structure of organization is divided into several stage for team } \\
\text { management and multi-division. When a problem cannot be resolved, the } \\
\text { problem will passing to the higher authorities, but the duration of the problem to } \\
\text { settle down take a long time and without any discussion with others team. There } \\
\text { is difficult to team members to get a view from the top management or even } \\
\text { cooperation".-Rl".-Rl }\end{array}$ \\
\hline
\end{tabular}

There are three dimensions to the communication problems discussed by the construction project managers in this study. The critical points in managing IBS projects are identified by a majority of interviewees as the quality of information and knowledge, a lack of skill and attitude-related issues, and an organizational structure. Firstly, all agreed that managing an IBS project is challenging compared to the conventional system. For instance, without the 
appropriate quality of information and knowledge, the structure and design of the prefabricated components could be affected, due to the lack of readiness and exposure among industry players toward IBS technology and practitioner incentive programs. For the second dimension, a lack of skill and attitude is highlighted is a critical problem, contributing to a lack of communication. In this case, the major problem of an organization failing to have a proper standard documentation and communication structure had an effect on worker performance. Regarding the last dimension, an organizational structure requires the removal of internal bureaucracy directed toward the achievement of organizational aims.

\section{CONCLUSION}

This paper has reviewed evidence regarding the challenge of communicating while managing an IBS construction project. It can be concluded that the challenges faced by project managers to integrate relationships are difficult to achieve, requiring adequate internal and external communication to accomplish effective cross-cultural communication. Furthermore, an organization must also be more innovative and continually introduce plans with approaches that maintain their competitive advantages made through the managing of multicultural project teams. This study considered the building information modelling (BIM) approach, which would facilitate many tasks from different construction phases by allowing various people along construction project lifecycle process to collaborate. Supported in advance of cloud computing technology, this system could increase productivity and efficiency through the Internet and utilize devices (laptops, tablets, mobile phones, etc.) to deliver and share information without the need to develop new infrastructure and employee training. In these cases, three dimensions of communication problems in managing IBS construction were identified, namely, the quality of information and knowledge, a lack of skill and attitude-related issues, and an organizational structure. The effects of such problems could be minimized through a new communication approach, such as integrated project delivery, and supported by implementing mobile computing technology to improve information relevance, real-time sharing, and decisionmaking during the project lifecycle. In conclusion, the traditional ineffective procurement procedure requires restructuring to become more mutually integrated. The practitioner or organization realize that projects using collaborative approaches promote cooperative relationships, increasing productivity at various construction stages. Moreover, a littlepublished research capitalizes on the prospects of stakeholder attitude and behavioral change in relation to project success in Malaysia.

\section{ACKNOWLEDGEMENT}

The authors gratefully acknowledge the support given by Universiti Utara Malaysia for providing the funding under Research University Grant (Geran Top Down; S/O code: 12571).

\section{REFERENCES}

Abdul Nifa, F.A., 2013. Development of a Framework for Partnering through Aligning Organizational Cultures in the Malaysian Construction Industry. PhD Dissertation, University of Salford, Manchester

Abedi, M., Fathi, M.S., Mirasa, A.K., Rawai, N.M., 2016. Integrated Collaborative Tools for Precast Supply Chain Management. Scientia Iranica, Volume 23(2), pp. 429-448

Alashwal, A.M., Fong, P.S.W., 2015. Empirical Study to Determine Fragmentation of Construction Projects. Journal of Construction Engineering and Management, Volume 141(7), pp. 4015016

Barrett, D.J., 2006. Leadership Communication: A Communication approach for Senior-level 
Managers. In: Handbook of Business Strategy, Emerald Group Publishing, Rice University, Houston, pp 385-390

Barrett, P., Sexton, M., Lee, A., 2008. Innovation in Small Construction Firms. Routledge, London

Burke, R., Barron, S., 2014. Project Management Leadership: Building Creative Teams. John Wiley \& Sons, UK

Campbell, G.M., 2011. The Complete Idiot's Guide to Project Management. $5^{\text {th }}$ edition. Alpha Books, Indianapolis, USA

Construction Industry Development Board (CIDB), 2016. Construction Industry Transformation Programme (CITP) 2016-2020. Construction Industry Development Board Malaysia, Kuala Lumpur, Malaysia

Crabtree, B.F., Miller, W.L., (eds.), 1999. Doing Qualitative Research. $2^{\text {nd }}$ edition. Sage Publications, London

Dainty, A., Moore, D., Murray, M., 2006. Communication in Construction: Theory and Practice. Routledge

Fauzi, M.A., Hasim, S., Awang, A., Mohd Ridzuan, A.R., Yunus, J.N., 2017. Supply Chain Management on IBS Implementation in Klang Valley Construction Industry: Challenges and Issues. In: IOP Conference Series: Materials Science and Engineering, Volume, 291(1)

Firmawan, F., Othman, F., Yahya, K., 2012. Improving Project Performance and Waste Reduction in Construction Projects: A Case Study of a Government Institutional Building Project. International Journal of Technology, Volume 2(1), pp. 182-192

Hersey, P., Blanchard, K.H., 1972. Management of Organizational Behaviour: Utilizing Human Resources. $2^{\text {nd }}$ edition. Prentice-Hall, Englewood Cliffs

Irvine, A., Drew, P., Sainsbury, R., 2010. Mode Effects in Qualitative Interviews: A Comparison of Semi-structured Face-to-face and Telephone Interviews using Conversation Analysis. Research Works, 2010-03, Social Policy Research Unit, University of York, York

Ismail, Z.A., Mutalib, A.A., Hamzah, N. 2016. A Case Study of Maintenance Management Systems in Malaysian Complex and High-rise Industrialized Building System Buildings. International Journal of Economics and Financial Issues, Volume 6(3S), 28-35

Kassim, U., Walid, L., 2013. Awareness of the Industrialized Building System (IBS) implementation in Northern Malaysia - A Case Study in Perlis. Procedia Engineering, Volume 53, pp. 58-63

King, N., 2004. Using Templates in the Thematic Analysis of Text. Essential Guide to Qualitative Methods in Organizational Research, Volume 2, pp. 256-70

Meng, X., Boyd, P., 2017. The Role of the Project Manager in Relationship Management. International Journal of Project Management, Volume 35(5), pp. 717-728

Müller, R., Rodney Turner, J., Turner, J.R., 2010. Attitudes and Leadership Competences for Project Success. Baltic Journal of Management, Volume 5(3), pp. 307-329

Nawi, M.N.M., Lee, A., Mydin, M.A.O., Osman, W.N., Rofie, M.K., 2018. Supply Chain Management (SCM): Disintegration Team Factors in Malaysian Industrialised Building System (IBS) Construction Projects. International Journal of Supply Chain Management, Volume 7(1), pp. 140-143

Othman, M.K.F., Muhammad, W.M.N.W., Hadi, N.A., Azman, M.A., 2017. The Significance of Coordination for Industrialised Building System (IBS) Precast Concrete in Construction Industry. In: MATEC Web of Conferences, Volume 103, p. 03004. EDP Sciences

Saunders, M., Lewis, P., Thornhill, A., 2009. Research Methods for Business Students. Pearson Education, England 
Shukor, A.S.A., Muhammad, M.F., Khaderi, S.S., Halil, F.M., 2016. Supply Chain Integration: Establish the Appropriate Challenges in Improving Integrated SC in an Innovative Approach of IBS. Environment-Behaviour Proceedings Journal, Volume 1(3), 79-88

Sunindijo, R.Y., 2015. Project manager skills for improving project performance. International Journal of Business Performance Management, Volume, 16(1), pp.67-83 